\title{
¿Accuracy and Long-Term Stability Assessment of Inductive Conductivity Cell Measurements on Argo Floats 0
}

\author{
Nikolay P. Nezlin,${ }^{\mathrm{a}, \mathrm{e}}$ Mathieu Dever,${ }^{\mathrm{a}, \mathrm{b}}$ Mark Halverson,${ }^{\mathrm{a}}$ Jean-Michel Leconte, ${ }^{\mathrm{a}}$ Guillaume Maze, \\ Clark Richards, ${ }^{\mathrm{d}}$ IgOr ShKVORETS, ${ }^{\mathrm{a}}$ Rui ZHANG, ${ }^{\mathrm{a}}$ AND Greg JOHNSON ${ }^{\mathrm{a}}$ \\ ${ }^{a}$ RBR, Ltd., Ottawa, Ontario, Canada \\ ${ }^{\mathrm{b}}$ Woods Hole Oceanographic Institution, Woods Hole, Massachusetts \\ ${ }^{\mathrm{c}}$ IFREMER, Brest, France \\ ${ }^{\mathrm{d}}$ Bedford Institute of Oceanography, Dartmouth, Nova Scotia, Canada
}

(Manuscript received 24 April 2020, in final form 17 August 2020)

\begin{abstract}
This study demonstrates the long-term stability of salinity measurements from Argo floats equipped with inductive conductivity cells, which have extended float lifetimes as compared to electrode-type cells. New Argo float sensor payloads must meet the demands of the Argo governance committees before they are implemented globally. Currently, the use of CTDs with inductive cells designed and manufactured by RBR, Ltd., has been approved as a Global Argo Pilot. One requirement for new sensors is to demonstrate stable measurements over the lifetime of a float. To demonstrate this, data from four Argo floats in the western Pacific Ocean equipped with the RBRargo CTD sensor package are analyzed using the same Owens-Wong-Cabanes (OWC) method and reference datasets as the Argo delayed-mode quality control (DMQC) operators. When run with default settings against the standard DMQC Argo and CTD databases, the OWC analysis reveals no drift in any of the four RBRargo datasets and, in one case, an offset exceeding the Argo target salinity limits. Being a statistical tool, the OWC method cannot strictly determine whether deviations in salinity measurements with respect to a reference hydrographic product (e.g., climatologies) are caused by oceanographic variability or sensor problems. So, this study furthermore investigates anomalous salinity measurements observed when compared with a reference product and demonstrates that anomalous values tend to occur in regions with a high degree of variability and can be better explained by imperfect reference data rather than sensor drift. This study concludes that the RBR inductive cell is a viable option for salinity measurements as part of the Argo program.
\end{abstract}

KEYWORDS: Pacific Ocean; Salinity; Instrumentation/sensors; Profilers, oceanic; Quality assurance/control

\section{Introduction}

The Argo program consists of approximately 4000 autonomous profiling floats continuously operating in the World Ocean (Jayne et al. 2017; Roemmich et al. 2019). Its implementation started in 1999, and it has been providing global coverage of the upper $2000 \mathrm{~m}$ of the open ocean since 2006. More recently, Argo coverage has grown to include seasonal ice zones and marginal seas. Argo is a part of the Global Ocean Observing System, providing basic oceanographic information for process studies, ocean model data assimilation, validation, reanalysis, and forecasting (Legler et al. 2015).

๑ Denotes content that is immediately available upon publication as open access.

Supplemental information related to this paper is available at the Journals Online website: https://doi.org/10.1175/JTECH-D-200058.s1.

\footnotetext{
${ }^{\mathrm{e}}$ Current affiliation: Global Science \& Technology, Inc., Greenbelt, Maryland.

Corresponding author: Nikolay P Nezlin, nikolay.nezlin@ gmail.com
}

Data quality is a key asset of the Argo program: target accuracies for measurements are set to $2.5 \mathrm{dbar}$ for pressure, $0.005^{\circ} \mathrm{C}$ for temperature, and 0.01 for salinity (Riser et al. 2016). The main obstacle in achieving this goal is that autonomous floats cannot be recalibrated on a regular basis and, as such, indirect methods of data quality analysis and correction must be applied to achieve accurate results. For Argo data, quality control includes two steps: First, real-time quality control (RTQC) procedures are applied to the data collected by the floats, focusing on the detection and elimination of outliers (Schmid et al. 2007; Udaya Bhaskar et al. 2013; Wedd et al. 2015; Wong et al. 2020). These data are generally made freely available in near-real time (NRT), that is, within $24 \mathrm{~h}$. Second, a delayed-mode quality controlled (DMQC) analysis is conducted to produce high quality datasets suitable for oceanographic research. Delayed-mode (DM) analysis relies on Argo data experts to examine the data and apply corrections when necessary. DM products are available to users 6-12 months after collection.

Temperature and pressure are generally measured within the required accuracies throughout the life of a float (Abraham et al. 2013). The direct impact of uncertainties in temperature and pressure on salinity is $<0.006$, i.e., less than half the salinity target accuracy of 0.01 (see online supplemental section 1 ). The accuracy of salinity is challenging for two main reasons. First, biofilms can form on the conductivity cell, causing a change in the cell geometry, which ultimately impact conductivity measurements. Mitigation strategies are used to reduce biofouling, 
such as poisoning the water within the cell with tributyltinoxide (TBTO), as is routinely used in electrode-based conductivity cells. TBTO, however, is known to coat the electrodes inside the conductivity cell for the first few months of a deployment, before eventually washing off, thus unevenly impacting conductivity readings through time (Wong et al. 2020).

Second, mechanical failures can seriously impact measured conductivity. Recently, for example, large batches of conductivitytemperature-depth (CTD) instruments SBE41CP from Sea-Bird Scientific (SBE) have been found by DMQC operators and others to rapidly drift salty, potentially arising from the failure of the encapsulant used in the cell construction (see Argo Steering Team 2018, section 8). As a result, an essential part of DMQC process is the analysis and correction of salinity offset and drift using the standard "Owens-Wong-Cabanes" (OWC) method (Cabanes et al. 2016; Owens and Wong 2009).

Salinity measurements in the ocean are commonly made using either electrode or inductive conductometry principles. While electrode cells measure electrical resistance between the electrodes in direct contact with seawater, inductive cells function according to Faraday's law of induction (Relis 1947; Striggow and Dankert 1985). An electrical signal applied to the generating coil induces an electromagnetic current in the seawater present in the center of the cell. This current flows in a closed loop through a receiving coil. The received current is proportional to the resistance of the water, which is inversely proportional to conductivity. The measured conductivity is ultimately converted into practical salinity using the seawater equation of state (Fofonoff 1985; McDougall and Barker 2011).

Inductive conductivity cells possess key features that are particularly beneficial for autonomous observing systems (Halverson et al. 2020; Shkvorets and Johnson 2010). Specifically, inductive conductivity cells can be built with a low aspect ratio (short and wide), resulting in water freely flushing through the cell. Such a cell does not require a pump to mechanically circulate water through the measurement region, significantly lowering power consumption compared to sensors using pumped electrode conductivity cells. In contrast to electrode-based pumped systems, which have to turn off the pump near the surface to avoid clogging, inductive conductivity cells can measure all the way to the surface, providing access to important measurements at the ocean's boundary layer. Because inductive cells measure conductivity over a larger volume, the impact of light biofouling (e.g., oil films) has virtually no impact on conductivity readings, unlike electrode-based cells that have to rely on TBTO to get rid of even light biofouling.

The main disadvantage of inductive cells is that the measured conductivity is affected by the objects located within close proximity (especially the objects made of conductive materials like stainless steel). For the instruments like Argo floats, however, proximity effect can be eliminated by proper calibration after the float is assembled. Inductive cells are also impacted by the effect of high pressure, which modifies the cell's geometry, affecting conductivity measurements.

Inductive conductivity sensors produced by Falmouth Scientific, Inc. (FSI), were installed on the first experimental Profiling Autonomous Lagrangian Circulation Explorers (PALACE) floats in the 1990s and deployed mostly by the Woods Hole Oceanographic Institution (Bacon et al. 2001; Durand and
Reverdin 2005). However, the performance of Argo floats equipped with FSI CTD was substandard, and the cells were subsequently phased out (the last FSI-equipped Argo float was deployed in December 2006) (Abraham et al. 2013). The poor performance of FSI CTDs was associated with biofouling mitigation techniques (ablative coatings) that changed the cell geometry and caused conductivity drift. The need for mitigative measures resulted from the relatively long presence (sometimes longer than $24 \mathrm{~h}$ ) of the float at the ocean surface, which was required for data transmission through the ARGOS satellite system, a problem that no longer affects modern floats, as Iridium telemetry typically only requires surfacing time of 15-20 min. FSI CTDs also suffered from issues that are not inherent to inductive conductivity sensors. For example, a firmware fault in the data bin averaging algorithm resulted in a pressure bias that could not be corrected in postprocessing (Barker et al. 2011). As a result of the problems plaguing the FSI CTD, and perhaps a lack of interest from competing manufacturers, an overwhelming majority of CTD instruments installed on Argo profilers use Sea-Bird's electrode-based CTDs.

A series of recent setbacks and technological improvements have motivated the development of a new sensor package for Core Argo floats. The switch to Iridium telemetry, as previously mentioned, has significantly reduced the time a float spends at the surface, thus decreasing the need for biofouling mitigation. Additionally, pumpfree CTDs consume much less power, which directly translates into longer float lifetime. Also, there has been a call to diversify the sensor packages on Argo floats so that the program is not susceptible to "single points of failure" (Roemmich et al. 2019).

The goal of this study is to assess the long-term accuracy and stability of salinity measurements collected by four Argo floats equipped with the RBRargo inductive CTD manufactured by RBR, Ltd. (https://rbr-global.com/). All four floats were deployed in the western Pacific Ocean as either experimental or pilot-project Argo floats (Fig. 1). For this analysis, we rely on the standard Argo community OWC MATLAB toolbox (https://github.com/ArgoDMQC/matlab_owc) that is used among DMQC operators to determine salinity offset and drift. The OWC method, as well as most statistical methods, is not free from ambiguity and subjectivity. In an attempt to minimize subjectivity, we combine the OWC method with a custom-made MATLAB visualization toolbox designed to help Argo users to select appropriate settings for OWC processing and make defensible conclusions about accuracy and stability of conductivity sensors.

The paper is organized as follows: The dataset and methods for data analysis are described in section 2 . Section 3 presents the results of the analysis by first looking at the stability characteristics (i.e., offset and drift) calculated by the OWC method and comparing it to the initial accuracy assessments. These statistics are then compared to salinity drift and offset estimated during DMQC and applied to other floats operating in the same regions. Some methods are suggested to avoid misinterpreting the results of the OWC analysis. A discussion of the results is presented in section 4.

\section{Data and method}

a. Argo floats equipped with inductive conductivity sensors

Four Argo Teledyne Webb Research Autonomous Profiling Explorer (Apex) floats equipped with RBRargo CTDs 

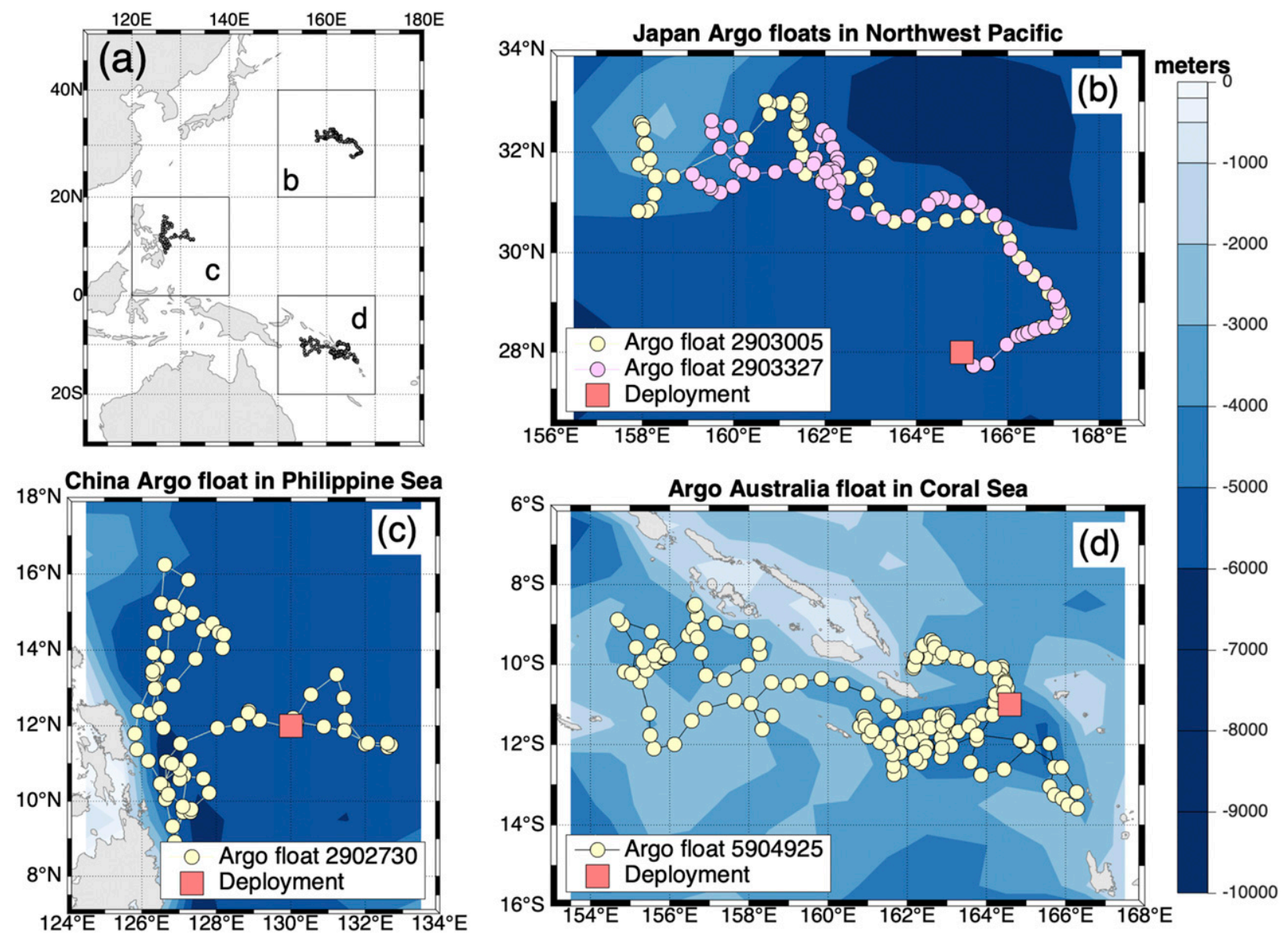

FIG. 1. Four Argo floats equipped with RBRargo CTDs operating in the western Pacific Ocean. (a) Rectangle outlines around each float indicate the regions where other Argo floats (deployed starting January 2011) were selected for comparison (section 3c) and correspond to (b)-(d). (b)-(d) Red squares indicate the deployment locations where the CTD profiles used for assessment of the initial accuracy of Argo salinity measurements (section $3 \mathrm{~b}$ ) were collected. The color shading indicates bathymetry.

with inductive conductivity cells were deployed in the western Pacific Ocean in 2015 and 2018 (Fig. 1; Table 1). The RBRargo CTD design changed in 2016, meaning the CTD on float 5904925 differs from the CTD on floats 2903005, 2903327, and 2902730 (Fig. 2). The 2016 redesign was undertaken to remove a mechanical design flaw in C-cell (the presence of an air gap between the holding ceramic insert cap and the inner assembly of the cell) and to improve the dynamic performance of the RBRargo CTD. Two modifications were made: 1) the thermistor was

TABLE 1. Four Argo floats with RBRargo CTDs operating in the Pacific Ocean. Asterisks: During the starting 2-month period, both Japan Argo floats operated at 1-day cycles and, starting on 28 Mar 2018, switched to 10-day cycles. To avoid overweighting of the starting period in the drift assessment, one of every 10 consecutive profiles was selected for both floats before 28 Mar 2018. Here, WMO ID indicates the World Meteorological Organization Argo float identifier.

\begin{tabular}{|c|c|c|c|c|c|c|}
\hline $\begin{array}{c}\text { Float } \\
\text { WMO ID }\end{array}$ & Region & $\begin{array}{c}\text { Deployment } \\
\text { date }\end{array}$ & $\begin{array}{l}\text { Deployment } \\
\text { coordinates }\end{array}$ & Vessel & Operator & $\begin{array}{c}\text { No. of cycles } \\
\text { analyzed }\end{array}$ \\
\hline 5904925 & Coral Sea & 24 Jul 2015 & $10.98^{\circ} \mathrm{S} ; 164.57^{\circ} \mathrm{E}$ & $\mathrm{R} / \mathrm{V}$ Cassiopee & $\begin{array}{l}\text { Australian Commonwealth } \\
\text { Scientific and Industrial } \\
\text { Research Organization } \\
\text { (CSIRO) }\end{array}$ & 148 \\
\hline 2903005 & Northwest Pacific & 3 Feb 2018 & $27.999^{\circ} \mathrm{N} ; 165.003^{\circ} \mathrm{E}$ & R/V Keifumaru & Japan Agency for Marine- & $61 *$ \\
\hline 2903327 & & & & & $\begin{array}{l}\text { Earth Science and } \\
\text { Technology (JAMSTEC) }\end{array}$ & $61 *$ \\
\hline 2902730 & Philippine Sea & 11 Jan 2018 & $11.98^{\circ} \mathrm{N} ; 129.998^{\circ} \mathrm{E}$ & $\begin{array}{c}\mathrm{R} / \mathrm{V} \mathrm{Ke} \mathrm{Хuе} \\
\text { San Нао }\end{array}$ & $\begin{array}{c}\text { China Second Institute of } \\
\text { Oceanography (CSIO) }\end{array}$ & 69 \\
\hline
\end{tabular}



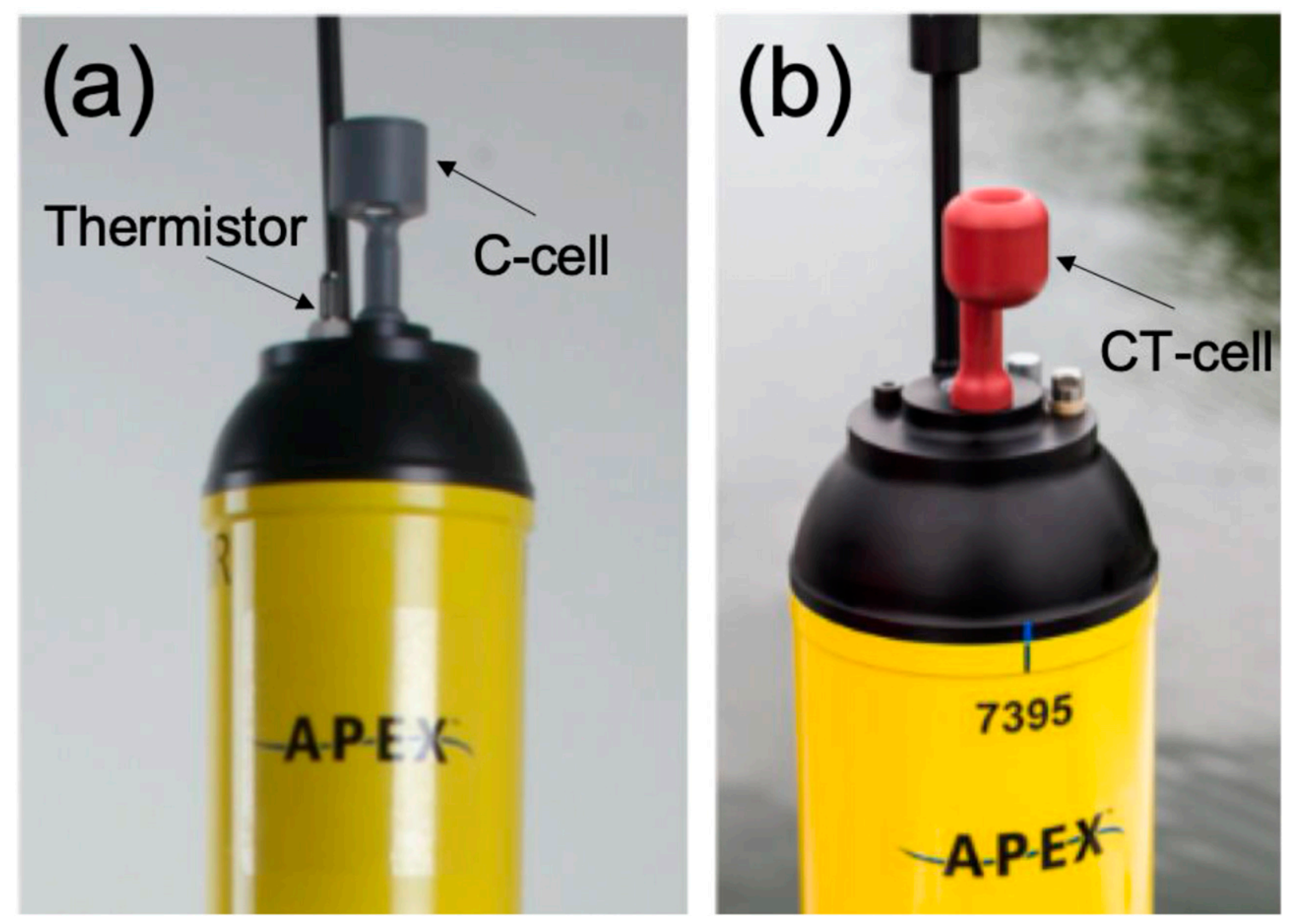

FIG. 2. Photographs of (a) the RBRargo CTD with inductive conductivity cell ("C-cell") (previous to 2016) and (b) the current inductive cell ("CT-cell"). The thermistor on the CT-cell is collocated with the conductivity cell; however, in the photograph it is on the far side of the cell and therefore is not visible. The photographs were provided through the courtesy of Teledyne Marine.

moved onto the conductivity cell itself, thereby eliminating the time lag from spatial mismatches of the sensors, and 2) the body of the cell was optimized to ensure the thermistor samples undisturbed water (Argo Steering Team 2018). Both CTD-cell designs measure conductivity through induction.

All Argo floats operate on a nominal 10-day cycle. For most of that cycle, they drift at a "parking depth," typically $1000 \mathrm{~m}$. Once in each cycle, the float dives to a 2000-m depth by changing its buoyancy and then performs an upcast profile measuring the Core Argo variables (pressure, temperature, and conductivity) up to the ocean surface. At the surface, the information is transmitted via satellite, and then the float descends back to its parking depth. The battery capacity of the float allows for at least 150 CTD profiles, which gives the float a theoretical 4-yr lifespan assuming a 10-day cycle.

Argo data telemetered via satellite are transmitted to one of the 11 Argo regional Data Assembly Centers (DAC) where they are checked for outliers by coarse semiautomatic RTQC tests (Wong et al. 2020). This data product, referred to as NRT, is then sent to Argo Global Data Assembly Centers (GDACs) and made publicly available within $24 \mathrm{~h}$. DMQC analysis is then performed by DACs to produce a delayed-mode data product, available within 12 months after observation. During the DMQC analysis, salinity observations are carefully checked by experts and, if necessary, corrected using the OWC method, a standard method for the Argo community (Wong et al. 2020).

\section{b. Salinity offset and drift detection}

The OWC analysis is a statistical method developed to detect salinity drift correction and described in Owens and Wong (2009) and Cabanes et al. (2016). In this method, the salinity profiles observed by an Argo float are compared to reference data in the same region by using objective mapping (OM; Bretherton et al. 1976). In this study, we used separately two reference datasets approved and used by the Argo community and prepared by the Argo Data Management Team (ADMT) at the Coriolis Data Center: 1) shipboard CTD casts (ADMTCTD) and 2) DMQC-corrected Argo profiles collected during preceding years (ADMT-Argo). Both datasets are available for the members of the Argo program upon request to the Institut Français de Recherche pour l'Exploitation de la Mer (IFREMER). 
Based on the fact that water-mass structures can be defined by the temperature and salinity signature, the salinity measured by the Argo float is compared to the reference products along as many as 10 potential temperature isotherms, characterized by minimal salinity variations and "calibrated" by the weighted least squares method to minimize its difference from the reference. The weights for the calculation are proportional to the inverse of the OM errors such that less variable deep-layer climatology influences the "calibration" of float salinity more than those of the more variable surface and intermediate layers.

In the OM calculations, the selection of reference data for each profile and their respective weights depend on their distance from the observed profiles in space and time: highest weights are assigned to reference profiles most closely positioned and most contemporaneous to the float profile date, as well as those with measurements obtained on the same isobaths as the float profile (Böhme and Send 2005). OM is performed in two steps, by first fitting large-scale variability and then small-scale residuals. The parameters regulating these scales are referred to as decorrelation scales (or separation factors) and are subjectively selected by the user on the basis of his/her knowledge of the impact of these factors on the OM in the study region (Wong et al. 2003) (see details in the appendix). The OWC method is based on the assumption that any conductivity offset changes slowly over time; as a result, a piecewise linear fit of the profile-based corrections over the float time series is applied. The OWC analysis returns a set of salinity correction factors, one for each completed profile. The decision whether or not the statistical trends represent sensor drift or ocean variability, and in turn whether or not conductivity corrections should be applied, is made by the DMQC operator and involves some degree of subjectivity.

The key settings used in the OWC MATLAB toolbox for our analysis are listed in the appendix. The results are also put in perspective through a direct comparison between the salinity profiles collected by the four RBRargo floats operating in the Pacific Ocean with the closest salinity profiles from the ADMT-Argo and ADMT-CTD datasets (online supplemental section 2).

\section{c. Distinguishing between instrumental errors and oceanographic variability}

The results of the OWC output strongly depend on the quality of reference data. Anomalies in salinity measured by the float's CTD relative to water mass with different temperature-salinity characteristics can be easily misinterpreted as sensor drift, especially when reference data are sparse or inaccurate. The approach taken in this study relies on visualization tools designed to assist users to determine whether anomalies in measured salinity are caused by instrumental errors or oceanographic variability and, as such, avoid ambiguity in salinity drift detection. These visualizing tools include the following:

1) Plots showing (i) a time series of the "profile fit coefficients" (i.e., the disagreement between the salinity measured by Argo float and reference data calculated by the OWC method averaged over the 10 selected reference potential temperature levels) and (ii) a map showing the magnitude of the fit coefficients along the float trajectory. Such plots help to identify spatial coherency in discrepancies between the analyzed Argo measurements and the reference dataset, providing information on whether discrepancies should be attributed to errors in the reference data, or to sensor drift.

2) Diagrams comparing the objectively mapped reference salinity field calculated by the OWC method to a different reference data source. For this purpose, the nearest grid points of the Roemmich-Gilson (RG) (Roemmich and Gilson 2009) climatology and/or other monthly gridded datasets were used. Discrepancies between different reference sources support the hypothesis that large salinity anomalies might be due to erroneous reference data, rather than to sensor drift. RG climatology was selected because it is also based on the ADMT-Argo reference dataset but uses a different method for data interpolation. Other climatologies were also considered and resulted in similar conclusions (see online supplemental section 3 ).

3) Simplified OWC analysis of nearby contemporary Argo floats provides yet another indication of whether the computed salinity error emanates from the reference dataset used.

\section{Results}

\section{a. Salinity offsets and their dependence on reference data and time separation factors}

The OWC analysis, when run with the settings specified in the appendix against the two ADMT-CTD and ADMT-Argo reference databases, revealed no statistical trends in any of the four RBRargo float salinities. There were small differences between the salinities measured by the RBRargo and the reference data. When compared with the ADMT-CTD reference database, the salinity offsets were different from the offsets based on the ADMT-Argo reference database (Table 2). These differences result from different time periods when the reference data were collected (Fig. 3). Most CTD casts were collected during the long ( $>30 \mathrm{yr}$ ) period starting in the $1980 \mathrm{~s}$ (Figs. 3a3,3b3,3c3), while most Argo profiles were collected after 2005 (Figs. 3a4,3b4,3c4) and cover a comparatively short time period. The resulting disagreement could be associated with temporal salinity variations in the Pacific Ocean documented in previous studies (e.g., Boyer et al. 2005; Durack and Wijffels 2010; Helm et al. 2010).

The salinity offset for Argo Australia float 5904925 in the Coral Sea demonstrated significant salinity bias: from -0.0139 to -0.0167 when compared with ADMT-CTD and ADMTArgo reference data (Table 2). This offset exceeds the Argo accuracy limits (0.01) and may result from the fact that this float was equipped with the older RBRargo design (see section 2a and Fig. 2).

For the other three RBRargo floats equipped with the newer design (two Japan Argo floats in the northwest Pacific and one China Argo float in the Philippine Sea; see Table 1), OWC salinity offsets below the Argo accuracy limits were found 
TABLE 2. Salinity offsets calculated by the OWC method at different reference datasets and time separation factors. Numbers in boldface font indicate the reference dataset and time separation factors selected for analysis.

\begin{tabular}{cccccc}
\hline \hline & Small/large time separation & Argo Australia & Japan Argo & Japan Argo & China Argo \\
IFREMER DMQC reference dataset & factors (yr) & 5904925 & 2903005 & 2903327 & 2902730 \\
\hline CTD 2019v01 & $1 / 3$ & -0.0152 & -0.0116 & -0.0139 & -0.0139 \\
& $3 / 10$ & -0.0167 & -0.0088 & -0.0107 & -0.0144 \\
Argo 2019v01 & $\mathbf{1 0 / 3 0}$ & $-\mathbf{0 . 0 1 5 2}$ & $-\mathbf{0 . 0 0 7 7}$ & $-\mathbf{0 . 0 0 7 5}$ & $-\mathbf{0 . 0 0 7 6}$ \\
& $1 / 3$ & -0.0139 & -0.0212 & -0.0258 & 0.0024 \\
& $3 / 10$ & -0.0141 & -0.0156 & -0.0188 & 0.0054 \\
& $10 / 30$ & -0.0147 & -0.0196 & -0.0213 & 0.0014 \\
\hline
\end{tabular}

when compared to the ADMT-CTD dataset with long (10-30 years) time separation factor (Table 2).

The dependence of the OWC results on other settings (see the appendix) was small. For all four floats, minimum offsets were found at the spatial separation factors (small/large) of
$2 \% 4^{\circ}$ of latitude and longitude (Table 3). From these results, we chose the ADMT-CTD 2019v01 database as a source of reference data and the time separation factors (small/large) of 10/30 years for all four floats (Table 2). The resulting OWC output showed no significant statistical trends for all four floats,
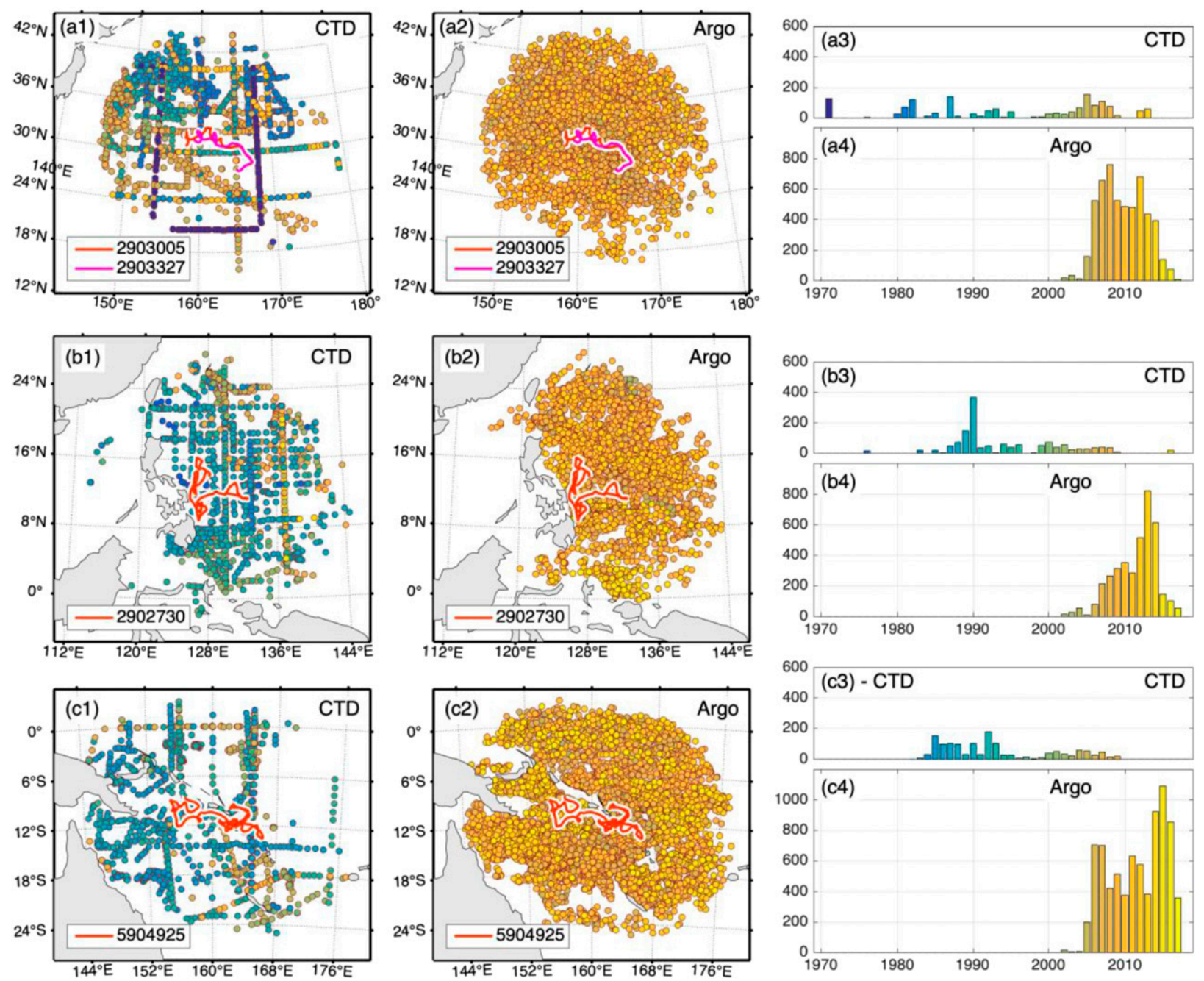

FIG. 3. Availability of reference data for OWC analysis of RBRargo floats: (a1)-(a4) Japan Argo; (b1)-(b4) China Argo and (c1)-(c4) Argo Australia. Shown are data for CTD casts [(a1), (a3), (b1), (b3), (c1), and (c3)] and DMQC-corrected Argo profiles [(a2), (a4), (b2), (b4), (c2), and (c4)]. Maps [(a1), (a2), (b1), (b2), (c1), and (c2)] demonstrate the locations of reference data; histograms [(a3), (a4), (b3), (b4), (c3), and (c4)] demonstrate the numbers of profiles collected during different years. The color scale in the maps and histograms indicates the years during which reference data were collected. 
TABLE 3. Salinity offsets calculated by the OWC method using the ADMT-CTD 2019v1 reference dataset at different spatial separation factors. Optimal time separation factors 10/30 years for all four floats were selected on the basis of Table 2. Numbers in boldface font indicate the spatial separation factors selected for analysis.

\begin{tabular}{ccccc}
\hline Small/large spatial separation factors $\left(^{\circ}\right)$ & Argo Australia 5904925 & Japan Argo 2903005 & Japan Argo 2903327 & China Argo 2902730 \\
\hline $0.5 / 1$ & -0.0170 & -0.0132 & -0.0141 & -0.0107 \\
$1 / 2$ & -0.0161 & -0.0101 & -0.0093 & -0.0100 \\
$\mathbf{2} / \mathbf{- 0 . 0 1 5 2}$ & -0.0176 & $-\mathbf{0 . 0 0 7 7}$ & $-\mathbf{0 . 0 0 7 5}$ & $-\mathbf{0 . 0 0 7 6}$ \\
$4 / 8$ & -0.0072 & -0.0076 & -0.0208 \\
\hline
\end{tabular}

which we interpret to mean that salinity, as measured by the RBRargo CTD, does not drift. We concluded that only salinity measured by one float (Argo Australia 5904925) required a correction in the form of a constant offset of -0.015 ; the other three floats did not need a salinity correction.

Direct comparison between the salinity profiles collected by the four RBRargo floats and the closest salinity profiles from the ADMT-Argo and ADMT-CTD datasets (online supplemental section 2) demonstrated that the differences in salinity in the beginning and the end of the RBRargo operation periods were within the limits of 0.01 Argo target accuracy for three floats (2903005, 2903327 and 2902730) and exceeded this threshold for the float 5904925 (Fig. S2.1 and Table S2.1 in the online supplemental material).

\section{b. Initial accuracy of floats}

The assessments of the initial accuracies of RBRargo salinity measurements indicated that they were within the Argo accuracy specification. Assessments were made by comparing the salinity measured in the first few cycles to CTD casts collected shortly after the float deployments (Fig. 4). The differences in salinity along isopycnals (potential density levels) were computed and averaged over the range of potential temperature below $5^{\circ} \mathrm{C}$ (Table 4). Only the Argo Australia float deployed in the Coral Sea demonstrated salinity offset exceeding the Argo accuracy limits $(>0.01)$, confirming the findings detailed in section 3a. For the three other floats, the initial accuracy was within the Argo requirements (Table 4). Comparing the first
Argo profiles to the World Ocean Atlas climatology of $1^{\circ}$ resolution (WOA1) (Garcia et al. 2018; Locarnini et al. 2019; Zweng et al. 2019) demonstrated larger differences than when compared with the CTD casts. In the northwestern Pacific and the Philippine Sea, the salinity measured by Argo floats varied mostly within the WOA1 climatology standard deviation limits (Figs. 4b,c). In contrast, salinity in the Coral Sea measured by the starting profile of the Argo float 5904925 exceeded both the CTD and WOA1 salinity variation limits within the entire deep $\left(\theta<5^{\circ} \mathrm{C}\right)$ layer (Fig. 4a).

\section{c. In situ drift and offset corrections for RBRargo compared to electrode-based CTDs}

To put the RBRargo salinity drift analysis in context, we assessed the long-term stability of other Argo floats equipped with electrode-based SBE41/41CP. To compare the CTDs directly, Argo datafiles were downloaded from a GDAC for all floats that 1) operated starting 2011 in the same areas (the $20^{\circ} \times 20^{\circ}$ rectangles around the float trajectories in Fig. 1a) and 2) contained a sufficient number of DM data (at least 25 profiles). A total of 360 floats met these criteria; the median time of operation was about 4 years, and the median number of DM profiles was 175 (minimum of 27 profiles; maximum of 438 profiles). For each float, the salinity offsets used for DM correction were computed from the mean difference between the raw salinity (PSAL) and the adjusted salinity (PSAL_ADJUSTED) in all DM profiles. In about $16 \%$ of the Argo floats with electrode conductivity sensors (57/360),
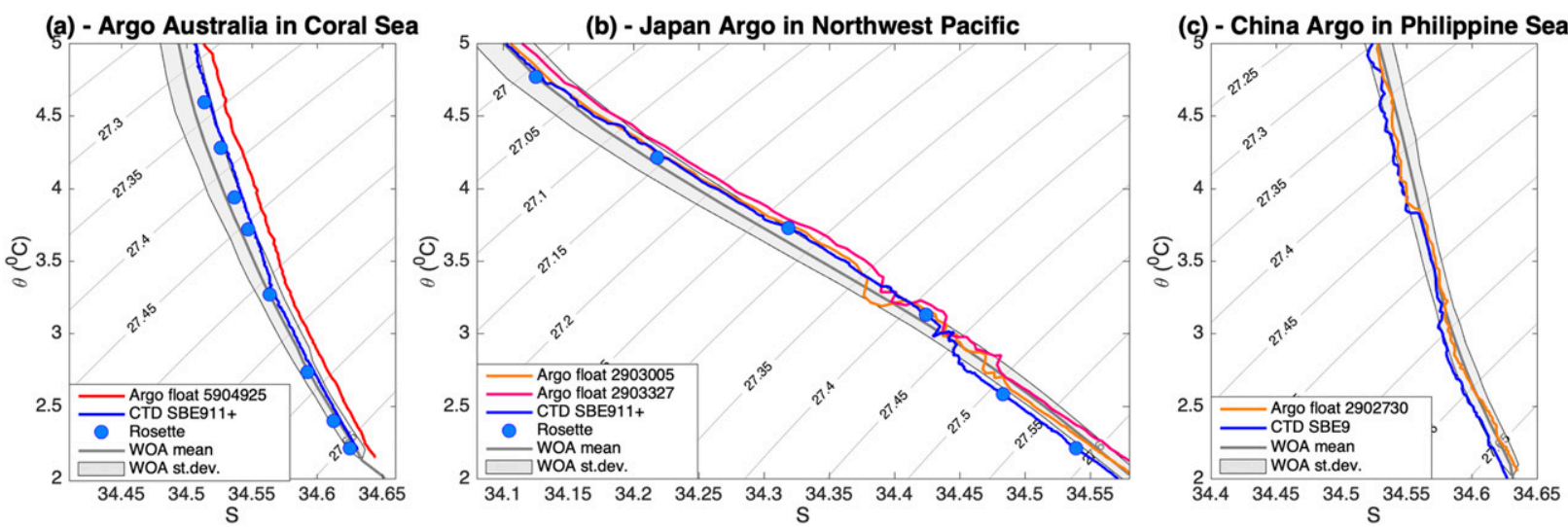

FIG. 4. Comparison between the starting profiles of the four Argo floats equipped with RBRargo CTDs, CTD casts collected when the float was deployed, and the World Ocean Atlas (WOA1) climatological data at the deployment location. The $X$ axes are practical salinity; $Y$ axes are potential temperature $\left({ }^{\circ} \mathrm{C}\right)$. 
TABLE 4. Assessment of the initial accuracy of the four Argo floats with RBRargo CTDs in the Pacific Ocean compared with the CTD and Rosette profiles collected in parallel with the float deployment, and the World Ocean Atlas data in the deployment locations. Numbers in boldface font exceed the Argo accuracy requirements.

Salinity offset in the layer with potential temperature $2^{\circ}-5^{\circ} \mathrm{C}$; averaged difference (reference - Argo), calculated along potential density levels

\begin{tabular}{lccccc}
\cline { 3 - 5 } \multicolumn{1}{c}{ Float } & Distance $(\mathrm{km})$ & Difference in time $(\mathrm{h})$ & Bottle & SBE911 & $\begin{array}{c}\text { World Ocean Atlas } \\
\text { (WOA1) }\end{array}$ \\
\hline Argo Australia 5904925 & 2.5 & 25.2 & $\mathbf{- 0 . 0 1 1 4}$ & -0.0081 & $\mathbf{- 0 . 0 1 2 4}$ \\
Japan Argo 2903005 & 0.38 & 23.1 & -0.0044 & -0.0034 & -0.0024 \\
Japan Argo 2903327 & 0.30 & 23.7 & -0.0090 & -0.0081 & -0.0066 \\
China Argo 2902730 & 0.38 & 19.2 & No data & -0.0044 & -0.0006 \\
\hline
\end{tabular}

the applied salinity offsets exceeded 0.01 . For $31 \%$ of floats (111/360), the salinity drift exceeded $0.0025 \mathrm{yr}^{-1}$.

One float with an RBRargo CTD (Argo Australia float $5904925)$ demonstrated a significant offset $(-0.015)$ relative to ADMT-Argo reference salinity (Fig. 5a), which is also the first float with RBR-equipped conductivity cell deployed in 2015. Since then, the design of the RBR conductivity cell was improved, with the thermistor located next to the conductivity cell (see Fig. 2b). The three RBRargo CTDs with new conductivity cell design (i.e., floats 2902730, 2903005, and 2903327) demonstrated offset within the Argo target accuracy (0.01). All four RBRargo CTDs demonstrated no salinity drift, although in many floats equipped with electrode conductivity cells salinity drift was detected and corrected during the DMQC analysis (Fig. 5b).

\section{d. Detecting problematic reference data in salinity drift assessment}

The OWC calibration method, when applied to data from four RBRargo, indicated that the CTDs are very stable over two or more years. However, there remain anomalies in the calibration salinity that warrant further investigation because, as a statistical method, OWC cannot determine whether variations in the calibration salinity are related to sensor problems or oceanographic variability. In this section, we describe in detail the results from the OWC output of four RBRargo floats and demonstrate the methods helping us to avoid this kind of ambiguity. The approach we use includes 1) identifying spatial coherency in discrepancies between the analyzed Argo measurements and the reference dataset, 2) comparing the reference salinity fields calculated by the OWC to a different reference data source, and 3) applying the OWC analysis to other nearby contemporary Argo floats.

\section{1) Argo Australia float 5904925 IN THE CORAL SEA}

For the Argo Australia float 5904925 deployed in the Coral Sea, the computed fit coefficients were stable during the entire 4-yr period of the float operation, demonstrating a high level of the sensor stability (Fig. 6a). A more detailed analysis demonstrated that the deviations from the average offset were spatially coherent, suggesting that the discrepancy might be due a specific oceanographic feature that was measured by the float, but not captured by the reference dataset. In fact, for
Argo Australia float 5904925, the geographical location of these deviations demonstrates that all profiles with salinity offsets larger than -0.015 were concentrated in the area to the northeast from the Solomon Islands, between $9^{\circ}$ and $12^{\circ} \mathrm{S}$ and between $161^{\circ}$ and $165^{\circ} \mathrm{E}$ (Fig. 6b). Additional evidence of shortcomings of the reference dataset arises from the comparison between the reference salinity calculated by the OWC OM algorithm on the basis of the ADMT-Argo dataset, and the RG (Roemmich and Gilson 2009) climatology (Fig. 6c). A large discrepancy was observed in June 2017 when the reference Argo dataset yielded lower salinity. Comparison between the ADMT-Argo reference data and other climatologies and gridded monthly products [World Ocean Atlas 2005-17 of $1^{\circ}$ resolution (WOA1) (Garcia et al. 2018; Locarnini et al. 2019; Zweng et al. 2019); Monthly Isopycnal and Mixed-Layer Ocean Climatology (MIMOC) (Schmidtko et al. 2013); CSIRO Atlas of Regional Seas (CARS2009) (Ridgway et al. 2002); In Situ Analysis System (ISAS13) (Gaillard 2015; Gaillard et al. 2016)] demonstrated similar disagreement during the same period (online supplemental section 3). This supports the hypothesis that the variations in the salinity profile fit coefficients calculated by the OWC method from the ADMT-Argo reference dataset is likely attributed to shortcomings in the reference data rather than to sensor drift.

\section{2) JAPAN ARgO FLOATS 2903005 AND 2903327 IN THE NORTHWEST PACIFIC}

The OWC output for the two Japan Argo floats located in the northwest Pacific did not show a statistically significant trend in salinity, and it returned salinity offsets below the Argo salinity target accuracy $(-0.0077$ for float 2903005 and -0.0075 for float 2903327; see Table 2 and Figs. 7a and 8a ).

Although the OWC output did not show a statistical trend in both Japan Argo floats, during the beginning of the times series, both floats 2903005 and 2903327 were located in the water with OWC reference salinity significantly higher than salinity measured by the Japan Argo floats (Figs. 7a and 8a) and the RG climatology (Figs. 7c and 8c) and other climatologies (section 3 of the online supplemental material and Figs. S3.2 and S3.3 therein). By July-August 2018, both floats drifted northward to the area with lower OWC reference salinity, which was evident from OWC salinity offsets (Figs. 7a and 8a) and comparison between OWC reference salinity to climatologies (Figs. 7c and 8c; online supplemental Figs. S3.2, S3.3). 

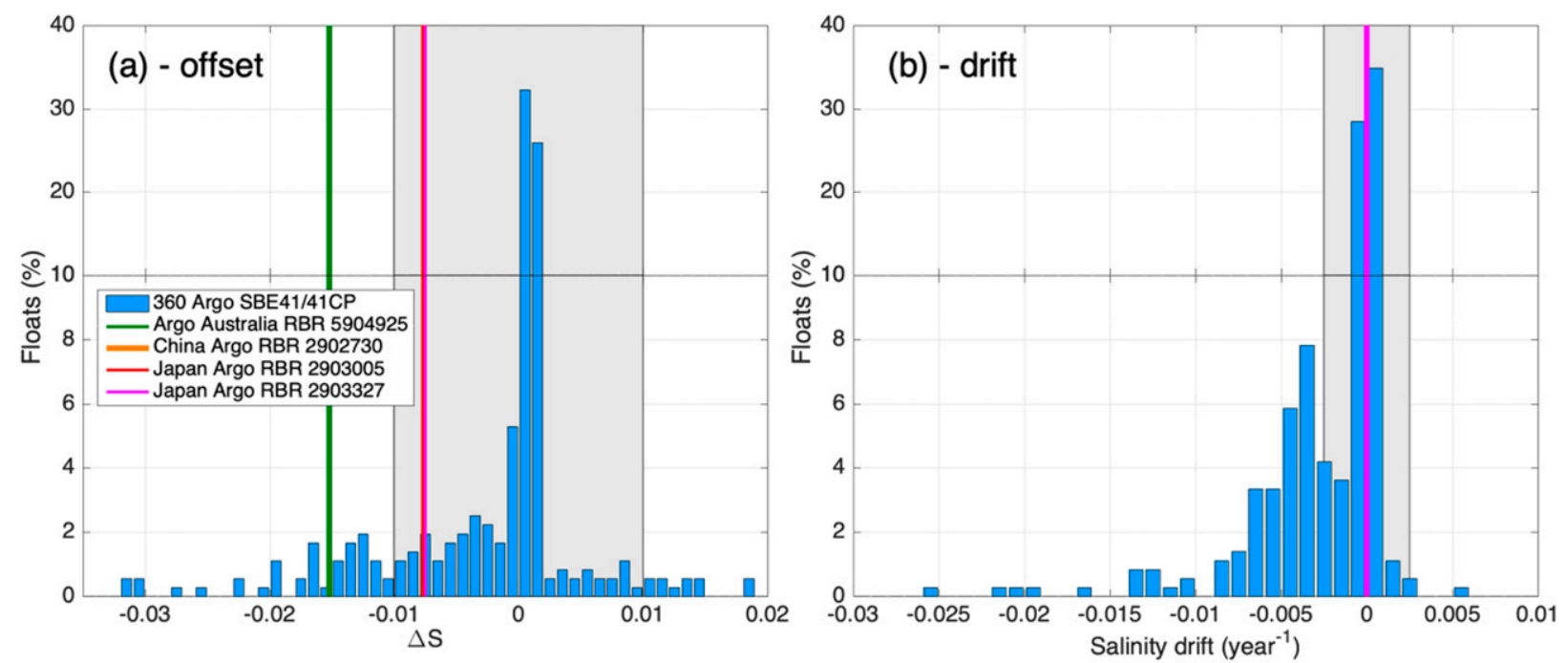

FIG. 5. The averaged salinity (a) correction offset and (b) drift (the slope of the linear change of the correction offset between the beginning and the end of the float lifetime) in four Argo floats with RBRargo CTDs and 360 Argo floats with electrode conductivity sensors operating in the same areas since 2011 (blue bars). Shaded areas show the target accuracy of Argo salinity measurements (0.01) in (a) and the stability limits of Argo salinity measurements $\left(0.01\right.$ in 4 years $\left.=0.0025 \mathrm{yr}^{-1}\right)$ in (b). Note that in (b) the drift estimates for all four RBRargo CTDs indicated in the legend are zero.

Starting April 2019, the float 2903005 was advected by strong currents and transported to west-southwest, covering about $240 \mathrm{~km}$ in less than a month (16 March-12 April 2019), resulting in a mean trajectory velocity greater than $10 \mathrm{~cm} \mathrm{~s}^{-1}$. This relocation of the float to a different region affected by the Kuroshio Extension was associated with water characterized by different salinity. Float 2903327 also moved to the region where float 2903005 was taken by strong current and transported to water with different temperature-salinity properties $\left(32^{\circ} \mathrm{N} ; 160^{\circ} \mathrm{E}\right)$. However, it arrived in that region about two months later, which might explain why the salinity variations observed in the data collected by float 2903005 were not observed by float 2903327.

\section{3) China Argo floAt 2902730 In the PhilipPine SEA}

The results of OWC analysis of the China Argo float 2902730 in the Philippine Sea demonstrate small (statistically insignificant) decreasing trend in the salinity offset (Fig. 9a). During that period, the float drifted to the north of $14^{\circ} \mathrm{N}$ and remained in this region until the end of the time
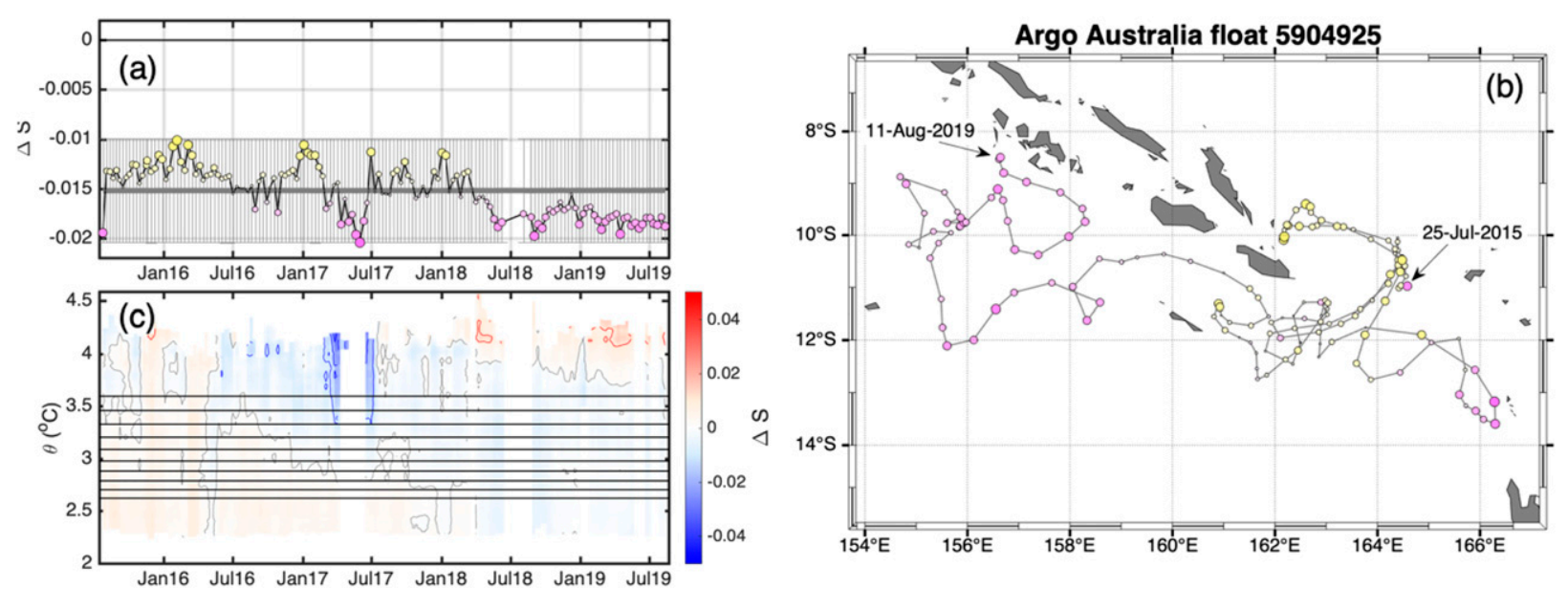

FIG. 6. (a) OWC profile fit coefficients for Argo Australia float 5904925, (b) geographical location of the profiles with different OWC fit coefficients. The size and color of the circles indicate the deviations of the profile fit coefficients from the constant offset. Arrows with dates indicate the start and end float positions. (c) The differences between the reference salinity calculated by the OWC method using the ADMT-CTD reference database and the Roemmich and Gilson (2009) climatology ( $Y$ scale is potential temperature). Horizontal lines in (c) show the 10 potential temperature levels with minimum salinity variations used for the OWC analysis. 

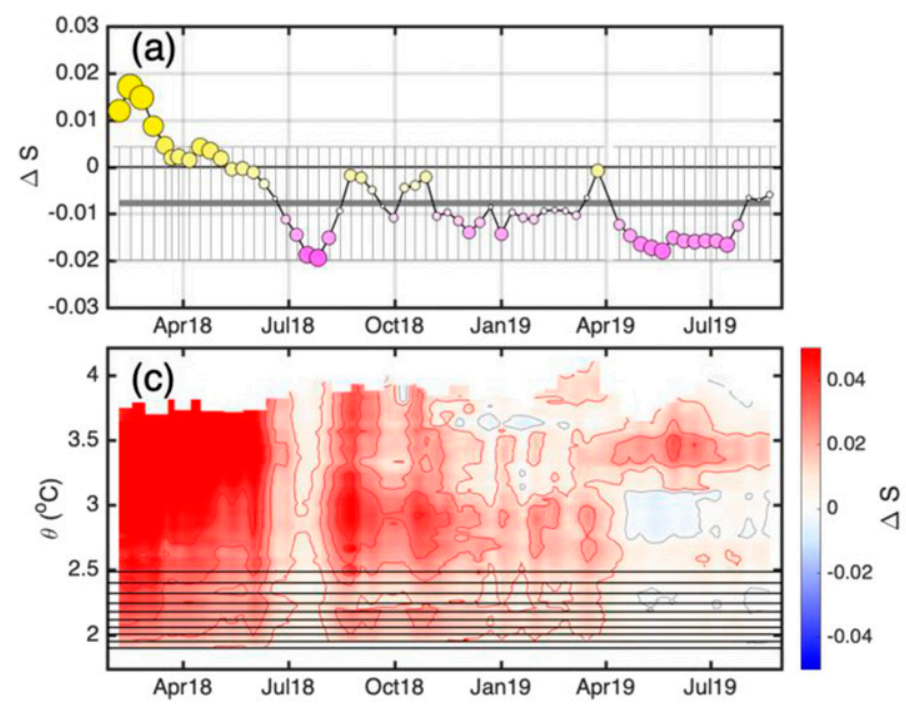

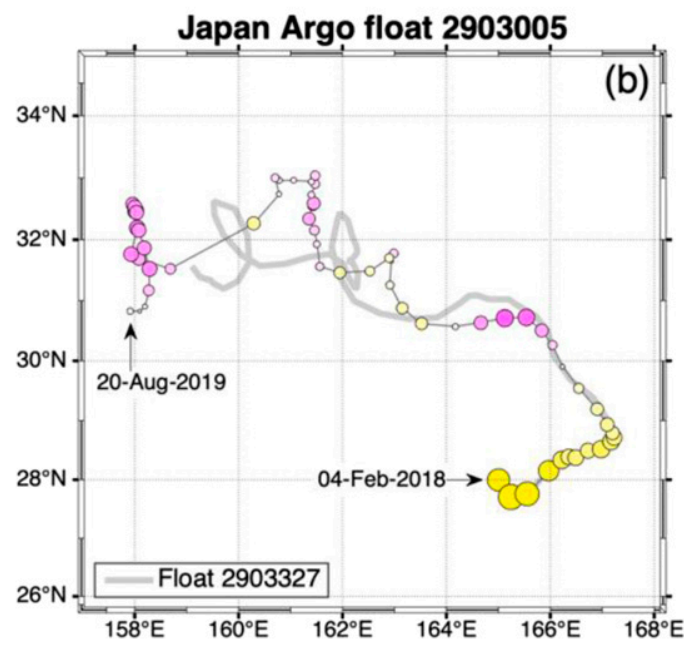

FIG. 7. As in Fig. 6, but for Japan Argo float 2903005. The gray line in (b) shows the trajectory of the Japan Argo float 2903327 deployed in parallel with the float 2903005 .

series (green rectangle in Fig. 9b). Comparison between the reference data and all five climatologies revealed increasing disagreement during that period (Fig. 9c and online supplemental section 3 ).

To determine whether the disagreement in salinity in this area is related to sensor drift, we extracted from the GDAC all data from floats profiling in the same area $\left(14^{\circ}-18^{\circ} \mathrm{N} ; 125^{\circ}-\right.$ $129^{\circ} \mathrm{E}$; green rectangles in Fig. 9b) during the same period (starting July 2019), which are composed of NRT data exclusively. Six floats with more than 10 profiles were selected for comparison (2902703, 2902708, 2902688, 2902683, 2902707 and 2901545). All six floats demonstrated similar decrease of the OWC profile fit coefficients around that small area. Results for float 2902683 are shown in Fig. 10; other floats are shown in online supplemental section 4 .

\section{Discussion}

This study investigates the accuracy and stability of salinity data collected by the RBRargo CTDs. When analyzed by the standard OWC method with default settings, all four RBRargo floats operating in the Pacific Ocean revealed no drift, while one of them (deployed in 2015 and equipped with C-cell of old design) demonstrated a calibration offset exceeding the limit of Argo accuracy specifications $(<0.01)$. All three RBRargo equipped with the newer CT-cells collected data within the
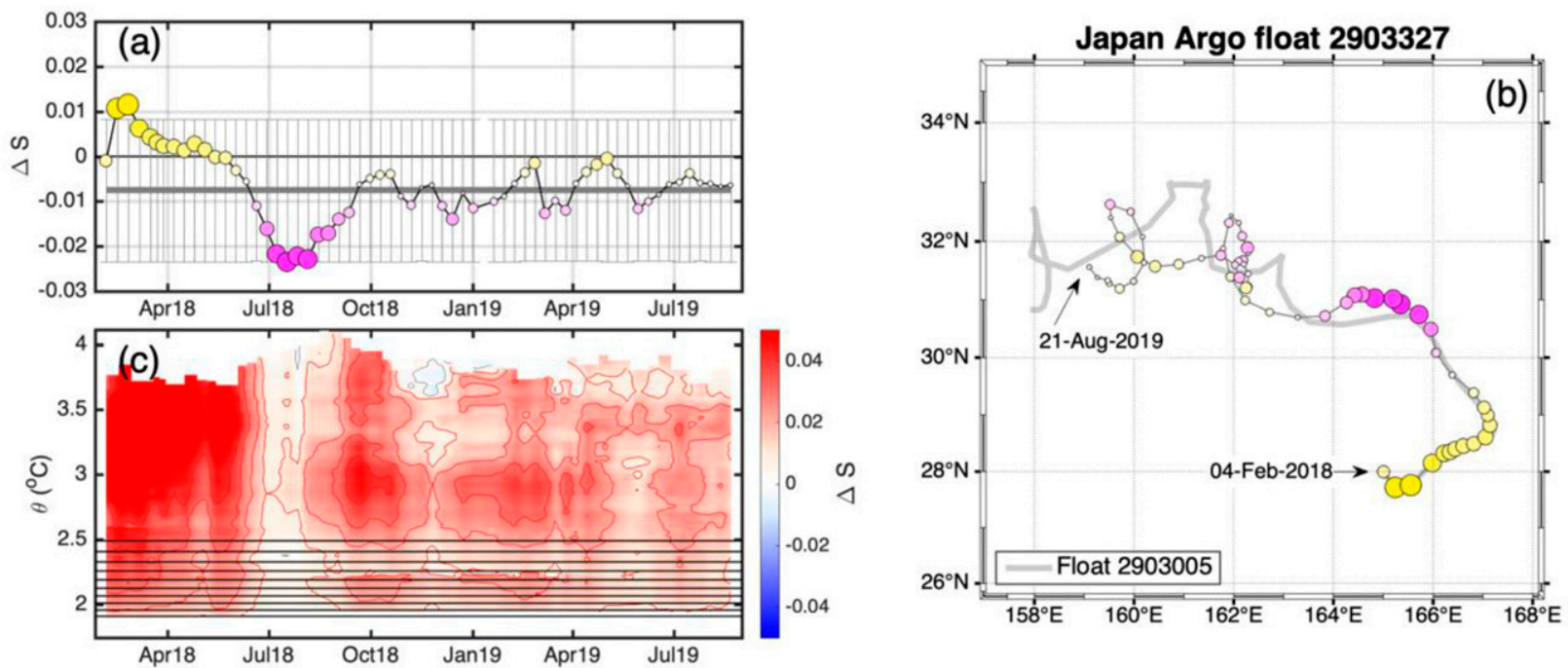

FIG. 8. As in Fig. 6, but for Japan Argo float 2903327. The gray line in (b) shows the trajectory of Japan Argo float 2903005 deployed in parallel with the float 2903327. 

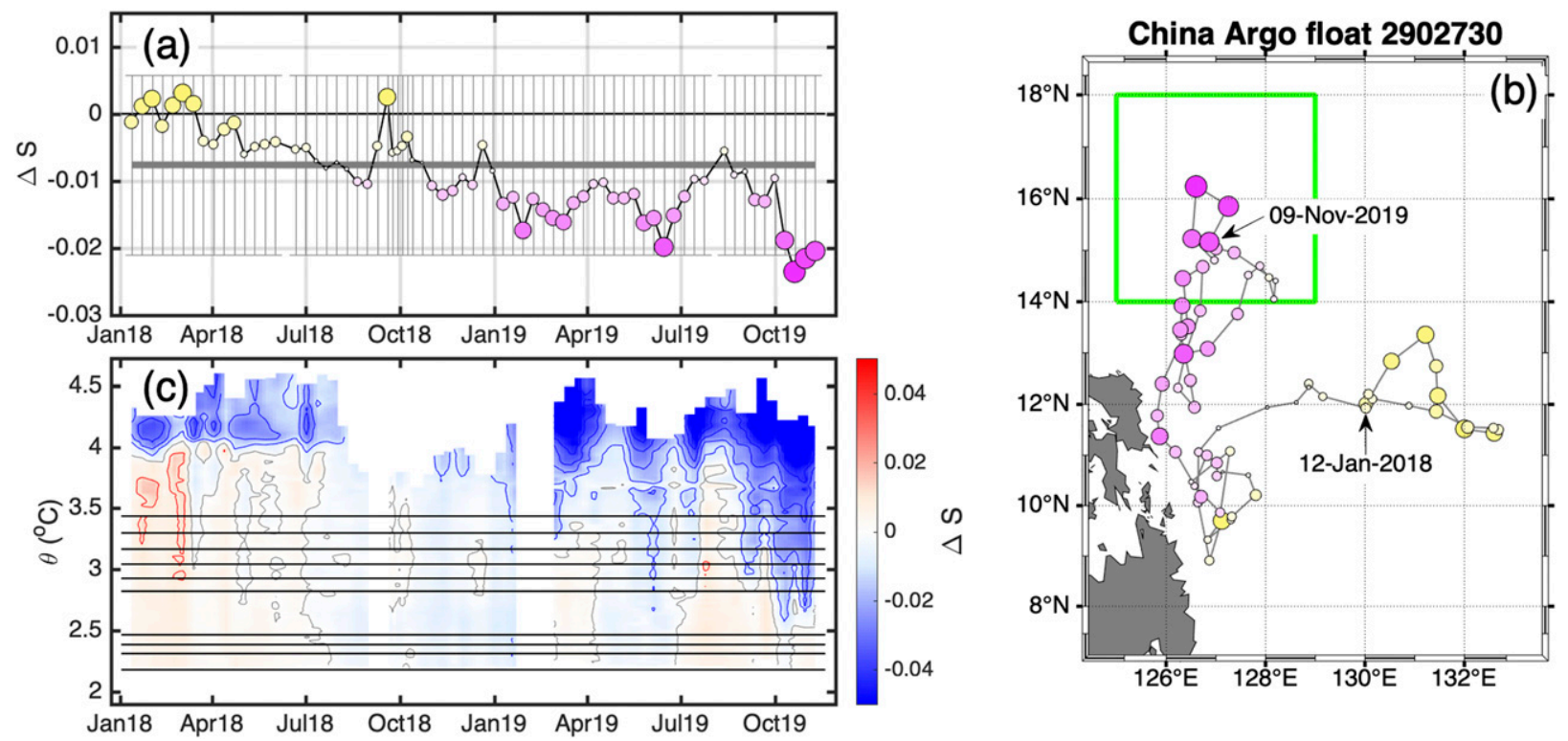

FIG. 9. As in Fig. 6, but for China Argo float 2902730.

Argo target accuracy. These characteristics are promising, and demonstrate, at least, performances that are comparable to that of Argo floats equipped with electrode conductivity sensors, which produce measurements that frequently require salinity offset and/or drift corrections. In fact, of 360 Argo floats operating in the same areas, over $30 \%$ demonstrated significant drift ( $>0.01$ in 4 years) that needed to be corrected during DMQC processing. Statistics for previous years reveal similar figures: for example, about $75 \%$ of Argo profiles in the
Coriolis Dataset for Reanalysis (CORA3) (1999-2010), had to be adjusted for pressure and/or salinity offset (Cabanes et al. 2013).

The OWC analysis of salinity stability for data collected by Argo floats demonstrated some caveats, which can result from the subjective decisions involved in the application of a salinity drift correction. These caveats are associated with limitations of reference data, which could naively be misinterpreted as sensor drift, especially in regions where oceanographic
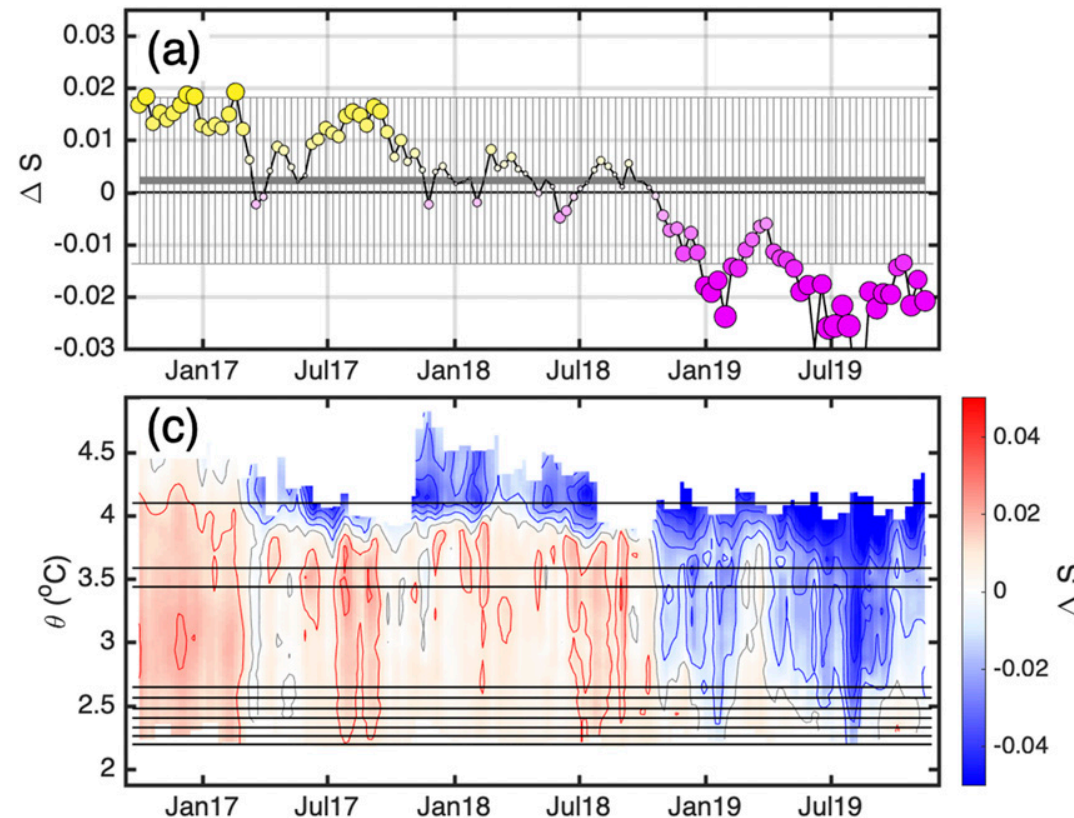

China Argo float 2902683

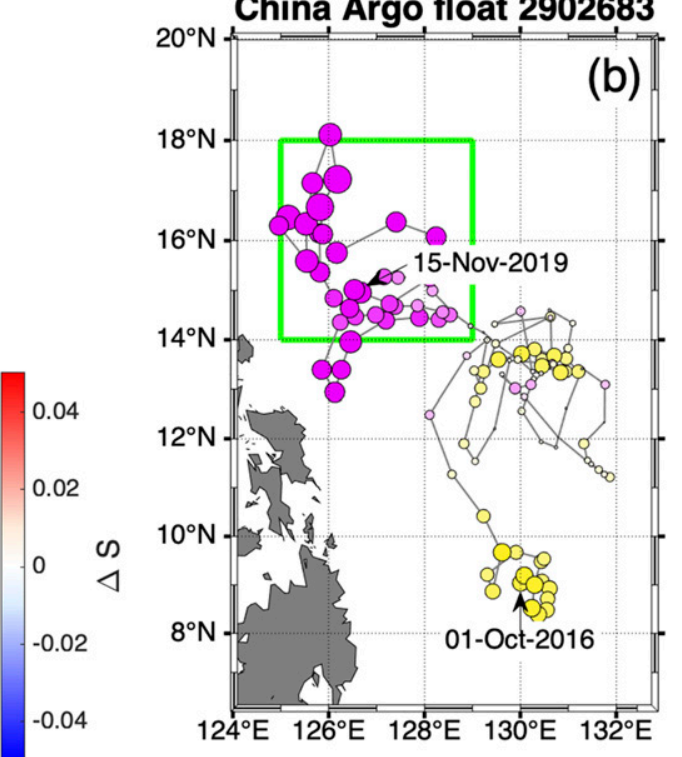

FIG. 10. As in Fig. 6, but for China Argo float 2902683 with SBE41 CTD operating in the same area and the same time with the China Argo float 2902730 (Fig. 9). 

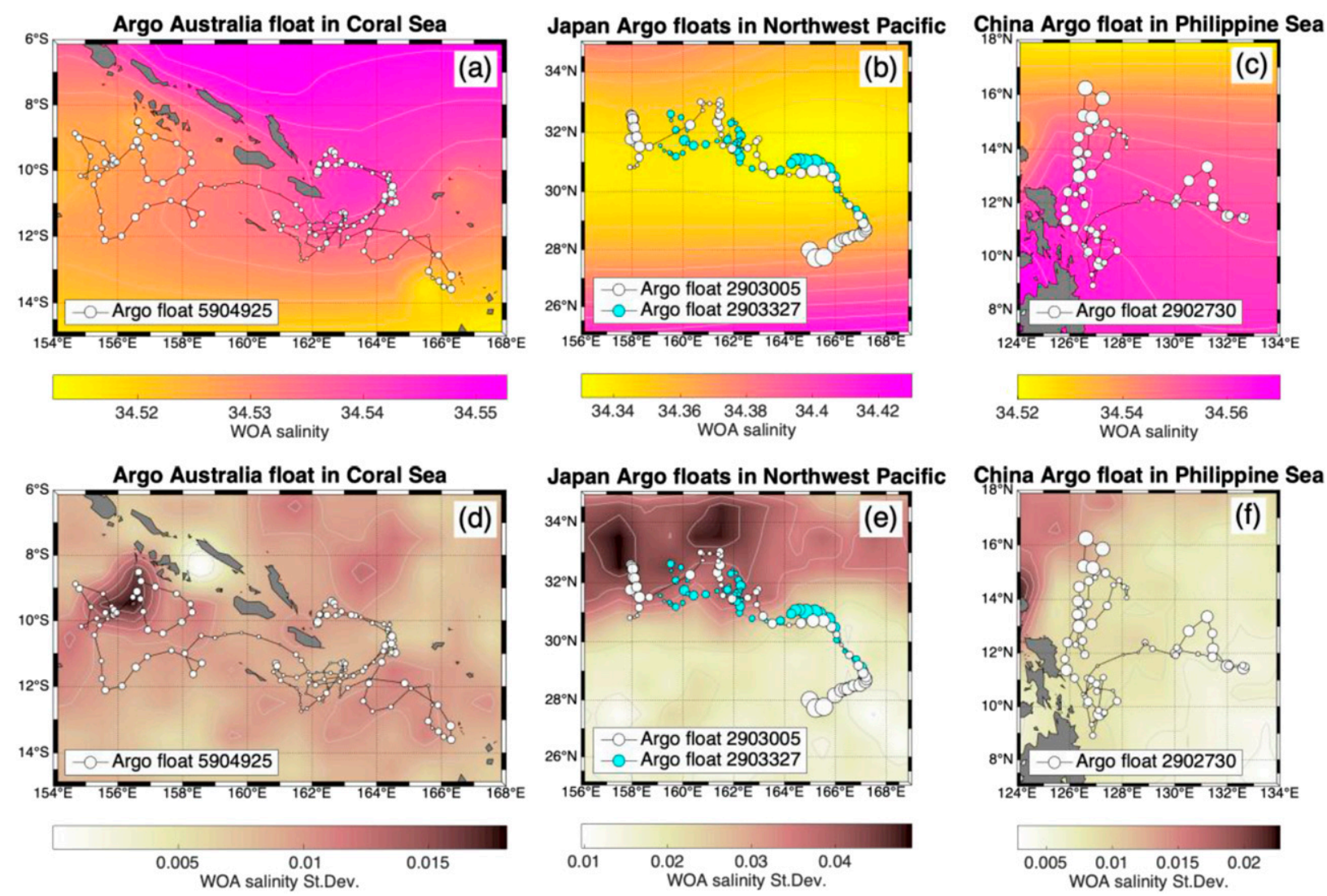

FIG. 11. World Ocean Atlas (Garcia et al. 2018) salinity (a)-(c) means and (d)-(f) standard deviations averaged in the 1000-1200-dbar layer in (left) the Coral Sea, (center) the northwest Pacific, and (right) the Philippine Sea, where the Argo floats with RBRargo CTDs operated. The size of circles along the float trajectories is proportional to the differences between the profile fit coefficients and the mean offsets calculated by the OWC method (similar to Figs. 6b-9b).

conditions can change over relatively short time scales (e.g., from months to year). The likelihood of a float encountering salinities different from the reference data is expected to be higher in these more variable areas with high concentration of mesoscale eddies around strong oceanic fronts (Chelton et al. 2011; Rhines 2001; Zhang et al. 2014). These regions are characterized by high gradients and increased variability of salinity in deep layers selected by the OWC analysis. This is illustrated by the patterns of geographical distribution of WOA1 salinity mean and standard deviation averaged over the 1000-1200 dbar layer (Fig. 11). In the Coral Sea, the most problematic area (in terms of reference salinity) was the region between the Solomon Islands and Vanuatu (Figs. 6b and 11a,d). The intermediate waters $(>700$ dbar) in that area are dominated by the low-salinity Antarctic Intermediate Water (AAIW) transported from the south (Gasparin et al. 2014; Qu and Lindstrom 2004). The northern extension of the AAIW terminates in a strong salinity front (Sokolov and Rintoul 2000) (Fig. 11a). We hypothesize that, during the objective mapping, low salinity measured to the south of this sharp gradient added negative bias to the reference data to the north resulting in the observed disagreement in Fig. 6b.
The disagreement between the salinity measured by the Japan Argo float and the reference data (Figs. 7a,b) increased when the float drifted northwest to the area affected by the Kuroshio Extension characterized by low and variable salinity (Qiu 2001) (Fig. 11e). A similar pattern was observed in the Philippine Sea where the China Argo float was drifting northward to the area where the main part of the Pacific North Equatorial Current bifurcates and feeds the northward flowing Kuroshio and the southward flowing Mindanao Current (Qiu and Lukas 1996; Wang et al. 2015). Salinity in the northern part of the Philippine Sea is lower and more variable as compared to the area to the south (Figs. 11c,f) (Zhou et al. 2018), and the northward trajectory of the Argo float resulted in gradual increase of the disagreement between the measurements and the references (Figs. 9a,b).

The importance of reference data for salinity drift assessment was evident from the beginning of the Argo program (Gaillard et al. 2009; Kobayashi and Minato 2005). Previous studies demonstrated an increase in the number of Argo profiles erroneously attributed as suspicious in dynamic and weakly stratified regions like the North Atlantic (Böhme and Send 2005; Cabanes et al. 2016), high eddy kinetic energy regions such as western boundary currents (Jia et al. 2016; Wang et al. 2013), or 
TABLE A1. Salinity offsets calculated by the OWC method using the ADMT-CTD 2019v01 reference dataset within different layers. Optimal time separation factors (small/large) of 10/30 years were selected on the basis of Table 2. Spatial separation factors (small/large) of $2 \% 4^{\circ}$ latitude and longitude were selected on the basis of Table 3 .

\begin{tabular}{ccccc}
\hline \hline Layer & Argo Australia 5904925 & Japan Argo 2903005 & Japan Argo 2903327 & China Argo 2902730 \\
\hline $1000-2000 \mathrm{dbar}$ & -0.0152 & -0.0077 & -0.0075 & -0.0076 \\
$1250-2000 \mathrm{dbar}$ & -0.0139 & -0.0075 & -0.0077 & -0.0082 \\
$1500-2000 \mathrm{dbar}$ & -0.0120 & -0.0079 & -0.0078 & -0.0089 \\
$1750-2000 \mathrm{dbar}$ & -0.0110 & -0.0099 & -0.0094 & -0.0092 \\
\hline
\end{tabular}

during anomalous events such as El Niño-Southern Oscillation (ENSO) (Cabanes et al. 2013). This study also demonstrates the importance of long-term trends in salinity ( $\mathrm{Li}$ et al. 2019; Liu et al. 2019; Wang et al. 2017) which must be taken into account in OWC analysis. We see that increasing the OWC time separation factor causes the Argo DMQC reference databases to approach climatology, while current conditions are different from climatological values. Although a sufficient number of high-quality reference data and proper selection of parameter settings for OWC calculations are a primary requirement for a robust assessment of Argo sensor stability, visualization tools like the ones demonstrated here can provide significant help. We recommend these methods for Argo users and believe that they can help Argo community in its mission-collecting high-quality oceanographic observations.

\section{Summary and conclusions}

This study demonstrates that salinity measurements collected by Argo floats equipped with inductive conductivity cells are stable for both older and newer design of the RBRargo. While the older design, where conductivity cell and thermistor are separated in space, presents an offset slightly exceeding Argo accuracy specifications, the newer design that combines the conductivity and temperature sensors is proven to be within the Argo accuracy requirements. The Core Argo program currently depends mostly on the SBE41 and SBE41CP CTDs produced by a single manufacturer (Sea-Bird Scientific). While this allows relative consistency in the collected data, it exposes the entire Argo program to a "risk of single points of failure" (Roemmich et al. 2019). To mitigate this risk, the Argo program welcomes initiatives to establish alternative sensor payloads (Roemmich et al. 2019). This study assessed the performance of the RBRargo CTD as an alternative CTD, based on the small number of floats deployed to this date. The evaluation of the RBRargo CTD will, with no doubt, benefit from a larger number of floats equipped with the RBRargo. Sustaining the Argo quality target relies on the combination of good instrument performance, and on continuous monitoring of the Argo fleet, as demonstrated by the complex and intricate quality control of Argo data.

Acknowledgments. The data from the Argo Australia, China Argo, and Japan Argo floats used here were collected and are made freely available by the International Argo program and the national programs that contribute to it (Argo 2000). The
Argo Program is part of the Global Ocean Observing System. Author Dr. G. Maze was supported by the EARISE project, a European Union's Horizon 2020 research and innovation program under Grant Agreement 824131, Call INFRADEV-032018-2019: Individual support to ESFRI and other world-class research infrastructures. We acknowledge Susan Wijffels, who provided advice on reference climatologies, coordinated access to the data from Argo Australia float 5904925, and provided ship CTD data to evaluate the initial accuracy of the float. Toshio Suga and Shigeki Hosoda provided ship CTD data for assessing the initial accuracy of Japan Argo floats 2903005 and 2903327. We thank Zenghong Liu for coordinating access to ship CTD data and continued discussion regarding RBRargo CTD accuracy and stability. We thank IFREMER for providing us access to ADMTCTD and ADMT-Argo reference datasets. We thank Annie P. S. Wong for critical comments and recommendations in data analysis. We thank two anonymous reviewers whose suggestions were very constructive and greatly improved this paper. Last, we thank the Argo Steering Team for encouraging Argo member nations to take part in the RBR CTD Argo Global Pilot Project.

Data availability statement. The Argo data are freely available from the Argo program website (http://www.argo.ucsd.edu/ Argo_data_and.html).

\section{APPENDIX}

\section{The Decorrelation Scales/Separation Factors of the OM Process Used for Assessment of Salinity Offsets by OWC Method}

In OWC analysis, OM is performed in two steps, by first fitting large-scale variability and then small-scale residuals. The respective weights of reference data for each profile are calculated on the basis of their distance from the observed profiles in space and time: highest weights are assigned to reference profiles most closely positioned and most contemporaneous to the float profile date. The parameters regulating these weights are referred to as decorrelation scales (separation factors) and are selected by the user. In this study, we performed calculations with different spatial (latitude/longitude) and temporal separation factors and selected those of them which resulted in constant offsets most close to zero. As a result, the spatial separation factors equal to $2^{\circ}$ of latitude and longitude (small) and $4^{\circ}$ (large) were selected (Table 3 ).

The constant salinity offsets calculated by the OWC method revealed small but consistent dependence from the layer in 
TABLE A2. Parameters values used for OM interpolation (the file "ow_config.txt") in OWC analysis.

\begin{tabular}{|c|c|c|c|}
\hline & Parameter & OWC variable & Value \\
\hline 1 & Max no. of historical casts used in objective mapping & CONFIG_MAX_CASTS & 300 (default) \\
\hline 2 & Use/not use PV constraint & MAP_USE_PV & 0 \\
\hline 3 & Use SAF separation criteria & MAP_USE_SAF & 0 \\
\hline \multirow[t]{4}{*}{4} & Spatial decorrelation scales $\left({ }^{\circ}\right)$ & MAPSCALE_LONGITUDE_LARGE & 4 \\
\hline & & MAPSCALE_LONGITUDE_SMALL & 2 \\
\hline & & MAPSCALE_LATITUDE_LARGE & 4 \\
\hline & & MAPSCALE_LATITUDE_SMALL & 2 \\
\hline \multirow[t]{2}{*}{5} & Cross-isobath scales & MAPSCALE_PHI_LARGE & 0.5 (default) \\
\hline & & MAPSCALE_PHI_SMALL & 0.1 (default) \\
\hline \multirow[t]{2}{*}{6} & Temporal decorrelation scale (yr) & MAPSCALE_AGE & $1-10$ \\
\hline & & MAPSCALE_AGE_LARGE & $3-30($ see section $3 a)$ \\
\hline 7 & Exclude the top $\mathrm{xxx}$ dbar of the water column & MAP_P_EXCLUDE & 1000 \\
\hline 8 & Only use historical data that are within \pm yyy dbar from float data & MAP_P_DELTA & 250 (default) \\
\hline
\end{tabular}

which this analysis was performed (Table A1; online supplemental section 2 and Figs. S2.3a, S2.4a and S2.5a therein), demonstrating pressure effect on conductivity measurements of inductive cells.

Other settings used during the OM interpolation are listed in Table A2. The parameters regulating linear fit of the profilebased corrections were set to default values; that is, the number of breakpoints was selected automatically.

\section{REFERENCES}

Abraham, J. P., and Coauthors, 2013: A review of global ocean temperature observations: Implications for ocean heat content estimates and climate change. Rev. Geophys., 51, 450-483, https://doi.org/10.1002/rog.20022.

Argo, 2000: Argo float data and metadata from Global Data Assembly Centre (Argo GDAC). SEANOE, accessed 15 August 2000, https://doi.org/10.17882/42182.

Argo Steering Team, 2018: 19th Meeting of the International Argo Steering Team. Sidney, BC, Canada, Institute of Ocean Sciences, $159 \mathrm{pp}$.

Bacon, S., L. R. Centurioni, and W. J. Gould, 2001: The evaluation of salinity measurements from PALACE floats. J. Atmos. Oceanic Technol., 18, 1258-1266, https://doi.org/10.1175/15200426(2001)018<1258:TEOSMF $>2.0$. CO;2.

Barker, P. M., J. R. Dunn, C. M. Domingues, and S. E. Wijffels, 2011: Pressure sensor drifts in Argo and their impacts. J. Atmos. Oceanic Technol., 28, 1036-1049, https://doi.org/ 10.1175/2011JTECHO831.1.

Böhme, L., and U. Send, 2005: Objective analyses of hydrographic data for referencing profiling float salinities in highly variable environments. Deep-Sea Res. II, 52, 651-664, https://doi.org/ 10.1016/j.dsr2.2004.12.014.

Boyer, T. P., S. Levitus, J. I. Antonov, R. A. Locarnini, and H. E. Garcia, 2005: Linear trends in salinity for the World Ocean, 1955-1998. Geophys. Res. Lett., 32, L01604, https://doi.org/ 10.1029/2004GL021791.

Bretherton, F., R. Davis, and C. Fandry, 1976: A technique for objective analysis and design of oceanic experiments applied to MODE-73. Deep-Sea Res. Oceanogr. Abstr., 23, 559-582, https://doi.org/10.1016/0011-7471(76)90001-2.

Cabanes, C., and Coauthors, 2013: The CORA dataset: Validation and diagnostics of in-situ ocean temperature and salinity measurements. Ocean Sci., 9, 1-18, https://doi.org/10.5194/os-9-1-2013.
_, V. Thierry, and C. Lagadec, 2016: Improvement of bias detection in Argo float conductivity sensors and its application in the North Atlantic. Deep-Sea Res. I, 114, 128-136, https:// doi.org/10.1016/j.dsr.2016.05.007.

Chelton, D. B., M. G. Schlax, and R. M. Samelso, 2011: Global observations of nonlinear mesoscale eddies. Prog. Oceanogr., 91, 167-216, https://doi.org/10.1016/j.pocean.2011.01.002.

Durack, P. J., and S. E. Wijffels, 2010: Fifty-year trends in global ocean salinities and their relationship to broad-scale warming. J. Climate, 23, 4342-4362, https://doi.org/10.1175/2010JCLI3377.1.

Durand, F., and G. Reverdin, 2005: A statistical method for correcting salinity observations from autonomous profiling floats: An ARGO perspective. J. Atmos. Oceanic Technol., 22, 292301, https://doi.org/10.1175/JTECH1693.1.

Fofonoff, N. P., 1985: Physical properties of seawater: A new salinity scale and equation of state for seawater. J. Geophys. Res., 90, 3332-3342, https://doi.org/10.1029/JC090iC02p03332.

Gaillard, F., 2015: ISAS-13-CLIM temperature and salinity gridded climatology. SEANOE, accessed 12 March 2015, https:// doi.org/10.17882/45946.

—, E. Autret, V. Thierry, P. Galaup, C. Coatanoan, and T. Loubrieu, 2009: Quality control of large Argo datasets. J. Atmos. Oceanic Technol., 26, 337-351, https://doi.org/ 10.1175/2008JTECHO552.1.

— , T. Reynaud, V. Thierry, N. Kolodziejczyk, and K. Von Schuckmann, 2016: In-situ based reanalysis of the global ocean temperature and salinity with ISAS: Variability of the heat content and steric height. J. Climate, 29, 1305-1323, https://doi.org/10.1175/JCLI-D-15-0028.1.

Garcia, H. E., and Coauthors, 2018: World Ocean Atlas 2018 (prerelease). NOAA Product Documentation Rep., 20.

Gasparin, F., C. Maes, J. Sudre, V. Garcon, and A. Ganachaud, 2014: Water mass analysis of the Coral Sea through an optimum multiparameter method. J. Geophys. Res. Oceans, 119, 7229-7244, https://doi.org/10.1002/2014JC010246.

Halverson, M., E. Siegel, and G. Johnson, 2020: Inductive-conductivity cell. Sea Technology, Vol. 61, 24-27.

Helm, K. P., N. L. Bindoff, and J. A. Church, 2010: Changes in the global hydrological-cycle inferred from ocean salinity. Geophys. Res. Lett., 37, L18701, https://doi.org/10.1029/ 2010GL044222.

Jayne, S. R., D. Roemmich, N. Zilberman, S. C. Riser, K. S. Johnson, G. C. Johnson, and S. R. Piotrowicz, 2017: The Argo program: Present and future. Oceanography, 30 (2), 18-28, https://doi.org/10.5670/oceanog.2017.213. 
Jia, W., D. Wang, N. Pinardi, S. Simoncelli, A. Storto, and S. Masina, 2016: A quality control procedure for climatological studies using Argo data in the North Pacific western boundary current region. J. Atmos. Oceanic Technol., 33, 2717-2733, https:// doi.org/10.1175/JTECH-D-15-0140.1.

Kobayashi, T., and S. Minato, 2005: Importance of reference dataset improvements for Argo delayed-mode quality control. J. Oceanogr., 61, 995-1009, https://doi.org/10.1007/s10872-0060016-z.

Legler, D. M., and Coauthors, 2015: The current status of the realtime in situ Global Ocean Observing System for operational oceanography. J. Oper. Oceanogr., 8 (Suppl. 2), s189-s200, https://doi.org/10.1080/1755876X.2015.1049883.

Li, G., Y. Zhang, J. Xiao, X. Song, J. Abraham, L. Cheng, and J. Zhu, 2019: Examining the salinity change in the upper Pacific Ocean during the Argo period. Climate Dyn., 53, 60556074, https://doi.org/10.1007/s00382-019-04912-z.

Liu, C., X. Liang, R. M. Ponte, N. Vinogradova, and O. Wang, 2019: Vertical redistribution of salt and layered changes in global ocean salinity. Nat. Commun., 10, 3445, https://doi.org/ 10.1038/s41467-019-11436-x.

Locarnini, R. A., and Coauthors, 2019: Temperature. Vol. 1, World Ocean Atlas 2018, NOAA Atlas NESDIS 81, 52 pp.

McDougall, T. J., and P. M. Barker, 2011: Getting started with TEOS-10 and the Gibbs Seawater (GSW) Oceanographic Toolbox. SCOR/IAPSO Rep. WG127, 28 pp.

Owens, W. B., and A. P. S. Wong, 2009: An improved calibration method for the drift of the conductivity sensor on autonomous CTD profiling floats by $\theta-S$ climatology. Deep-Sea Res. I, 56, 450-457, https://doi.org/10.1016/j.dsr.2008.09.008.

Qiu, B., 2001: Kuroshio and Oyashio Currents. Encyclopedia of Ocean Sciences, J. H. Steele, S. A. Thorpe, and K. K. Turekian, Eds., Academic Press, 1413-1425.

_ - and R. Lukas, 1996: Seasonal and interannual variability of the North Equatorial Current, the Mindanao Current, and the Kuroshio along the Pacific western boundary. J. Geophys. Res., 101, 12 315-12 330, https://doi.org/10.1029/95JC03204.

Qu, T., and E. J. Lindstrom, 2004: Northward intrusion of Antarctic Intermediate Water in the western Pacific. J. Phys. Oceanogr., 34, 2104-2118, https://doi.org/10.1175/1520-0485(2004)034<2104: NIOAIW $>2.0 . \mathrm{CO} ; 2$.

Relis, M. J., 1947: An electrodeless method for measuring the low-frequency conductivity of electrolytes. M.S. thesis, Dept. of Electrical Engineering, Massachusetts Institute of Technology, $121 \mathrm{pp}$.

Rhines, P. B., 2001: Mesoscale eddies. Encyclopedia of Ocean Sciences, J. H. Steele, Ed., Elsevier, 1717-1730.

Ridgway, K. R., J. R. Dunn, and J. L. Wilkin, 2002: Ocean interpolation by four-dimensional least squares-Application to the waters around Australia. J. Atmos. Oceanic Technol., 19, 1357-1375, https://doi.org/10.1175/1520-0426(2002)019<1357: OIBFDW $>2.0 . \mathrm{CO} ; 2$.

Riser, S. C., and Coauthors, 2016: Fifteen years of ocean observations with the global Argo array. Nat. Climate Change, 6, 145153, https://doi.org/10.1038/nclimate2872.

Roemmich, D., and J. Gilson, 2009: The 2004-2008 mean and annual cycle of temperature, salinity, and steric height in the global ocean from the Argo program. Prog. Oceanogr., 82, 81100, https://doi.org/10.1016/j.pocean.2009.03.004.
— depth, multi-disciplinary array. Front. Mar. Sci., 6, 439, https:// doi.org/10.3389/FMARS.2019.00439.

Schmid, C., R. L. Molinari, R. Sabina, Y.-H. Daneshzadeh, X. Xia, E. Forteza, and H. Yang, 2007: The real-time data management system for Argo profiling float observations. J. Atmos. Oceanic Technol., 24, 1608-1628, https://doi.org/ 10.1175/JTECH2070.1.

Schmidtko, S., G. C. Johnson, and J. M. Lyman, 2013: MIMOC: A global monthly isopycnal upper-ocean climatology with mixed layers. J. Geophys. Res. Oceans, 118, 1658-1672, https:// doi.org/10.1002/jgrc.20122.

Shkvorets, I., and F. Johnson, 2010: Advantages in performance of the RBR conductivity channel with Delrin ${ }^{\mathrm{TM}} /$ ceramic induc- $^{-}$ tive cell. OCEANS 2010, Seattle, WA, MTS/IEEE, https:// doi.org/10.1109/OCEANS.2010.5664276.

Sokolov, S., and S. Rintoul, 2000: Circulation and water masses of the southwest Pacific: WOCE Section P11, Papua New Guinea to Tasmania. J. Mar. Res., 58, 223-268, https://doi.org/10.1357/ 002224000321511151.

Striggow, K., and R. Dankert, 1985: The exact theory of inductive conductivity sensors for oceanographic application. IEEE J. Oceanic Eng., 10, 175-179, https://doi.org/10.1109/ JOE.1985.1145085.

Udaya Bhaskar, T. V. S., R. V. Shesu, E. P. R. Rao, and R. Devender, 2013: GUI based interactive system for visual quality control of Argo data. Indian J. Geo-Mar. Sci., 42, 580586.

Wang, F., N. Zang, Y. Li, and D. Hu, 2015: On the subsurface countercurrents in the Philippine Sea. J. Geophys. Res. Oceans, 120, 131-144, https://doi.org/10.1002/2013JC009690.

Wang, G., L. Cheng, T. P. Boyer, and C. Li, 2017: Halosteric sea level changes during the Argo era. Water, 9, 484, https:// doi.org/10.3390/w9070484.

Wang, X., G. Han, W. Li, X. Wu, and X. Zhang, 2013: Salinity drift of global Argo profiles and recent halosteric sea level variation. Global Planet. Change, 108, 42-55, https://doi.org/10.1016/ j.gloplacha.2013.06.005.

Wedd, R., M. Stringer, and K. Haines, 2015: Argo real-time quality control intercomparison. J. Oper. Oceanogr., 8, 108-122, https://doi.org/10.1080/1755876X.2015.1087186.

Wong, A. P. S., G. C. Johnson, and W. B. Owens, 2003: Delayedmode calibration of autonomous CTD profiling float salinity data by $\theta-S$ climatology. J. Atmos. Oceanic Technol., 20, 308-318, https://doi.org/10.1175/1520-0426(2003)020<0308: DMCOAC $>2.0 . \mathrm{CO} ; 2$.

—_, and Coauthors, 2020: Argo quality control manual for CTD and trajectory data. Argo Doc., 63 pp., https://doi.org/ $10.13155 / 33951$.

Zhang, Z., W. Wang, and B. Qiu, 2014: Oceanic mass transport by mesoscale eddies. Science, 345, 322-324, https://doi.org/ 10.1126/science. 1252418 .

Zhou, C., W. Zhao, J. Tian, Q. Yang, X. Huang, Z. Zhang, and T. Qu, 2018: Observations of deep current at the western boundary of the northern Philippine Basin. Sci. Rep., 8, 14334, https://doi.org/10.1038/s41598-018-32541-9.

Zweng, M. M., and Coauthors, 2019: Salinity. Vol. 2, World Ocean Atlas 2018, NOAA Atlas NESDIS 82, 50 pp. 